\author{
ANÁLISE DO COMPORTAMENTO E PRAGMATISMO \\ BEHAVIOR ANALYSIS AND PRAGMATISM
}

\author{
JAY MOORE \\ UNIVERSITY OF WISCONSIN-MILWAUKEE, USA
}

\begin{abstract}
RESUMO
Para o pragmatismo, o significado de um conceito ou afirmação psicológica é encontrado em suas implicações práticas para os assuntos humanos. Não há qualquer suposição de que o conceito ou afirmação representa a Verdade sobre uma Realidade metafísica que está além da experiência e do comportamento humano. Os analistas do comportamento abraçam o pragmatismo e argumentam que uma consideração importante na psicologia é o grau em que um conceito ou afirmação psicológica contribui para uma ação efetiva no laboratório ou na prestação de serviços. A ação efetiva comumente assume a forma de previsão e controle.

Palavras-chave: pragmatismo, previsão e controle, mentalismo, níveis de análise, neurociência.
\end{abstract}

For pragmatism, the meaning of a psychological concept or statement is found in its practical implications for human affairs. Absent is any assumption that the concept or statement represents the Truth about a metaphysical Reality that lies beyond human experience and behavior. Behavior analysts embrace pragmatism, and argue that an important consideration in psychology is the degree to which a psychological concept or statement contributes to effective action in the laboratory or in service delivery. The effective action commonly takes the form of prediction and control.

Key words: pragmatism, prediction and control, mentalism, levels of analysis, neuroscience.

\footnotetext{
Este artigo foi retirado do material que desenvolvi ao longo dos anos para ajudar no meu próprio ensino sobre o tema do pragmatismo na análise do comportamento. Eu o ofereço na esperança que outros o acharão útil. De acordo com o objetivo instrucional do artigo, as referências são mínimas. Além disso, tanto a linguagem quanto os argumentos são mais informais do que em outros artigos. Peço desculpas e tolerância por parte dos leitores caso a execução do mesmo tenha ficado aquém do esperado. Posso apenas dizer que essas contingências ainda não deram conta de mim totalmente. A correspondência referente ao artigo deve ser endereçada ao autor em jcm@uwm.edu, ou em seu endereço residencial: 1861 E. Fox Lane; Fox Point, WI 53217; EUA.
}

Nota da editora: Artigo traduzido por César Antonio Alves da Rocha, aluno do Programa de Pós-Graduação em Psicologia, Universidade Federal de São Carlos (UFSCar). Bolsista de doutorado FAPESP (Processo \#2014/02981-1). 


\section{ANÁLISE DO COMPORTAMENTO E PRAGMATISMO}

O pragmatismo é uma orientação filosófica, embora suas implicações se estendam a outras formas de atividade intelectual. O presente artigo se ocupa de suas implicações para uma ciência do comportamento.

Em termos simples, o pragmatismo sustenta que o significado e o valor de conceitos e enunciados são mais proveitosamente avaliados em termos de suas consequências práticas no mundo dos assuntos humanos, tais como a medida em que ajudam na adaptação. O pragmatismo é frequentemente contrastado com visões tradicionais, nas quais filósofos constroem sistemas metafísicos complexos em um esforço para representar o que eles consideram ser a verdade sobre a realidade. Muitos dos filósofos clássicos se destacam nesse aspecto: Platão, Descartes, Kant. O pragmatismo sugere que esses esforços são equivocados. Quando as afirmações e os conceitos são científicos, o pragmatismo argumenta que seu significado e valor são uma questão de o que eles implicam para uma interação efetiva com a natureza, comumente por meio de previsão e controle.

\section{UMA BREVE HISTÓRIA DO PRAGMATISMO}

O pragmatismo tem uma longa história. Por exemplo, o polímata inglês Francis Bacon (1623/1937) é, às vezes, creditado com o pensamento pragmático por argumentar em favor da ciência como fundamentalmente preocupada em "moldar a natureza como uma bigorna" ( $p$. 413) e alcançar resultados que beneficiam os humanos através de ação direta e prática. Da mesma forma, o grande físico e filósofo austríaco Ernst Mach (1886/1959) disse certa vez: "Mesmo os caminhos da ciência ainda levam à boca" (p. 23) ${ }^{1}$. Nos tempos mais modernos, muitos importantes pensadores americanos no final do século XIX e início de 1900, que eram ativos tanto na psicologia quanto na filosofia, foram considerados pragmatistas. Dois desses pensadores foram John Dewey (e.g., 1896) e William James (e.g., 1892). Como ilustração, notamos que James enfatizou: "Todas as ciências naturais visam a previsão e o controle práticos e em nenhuma delas isso é mais verdadeiro do que na psicologia atual" (p. 148). James prosseguiu argumentando que o que "todo educador, todo superintendente de asilo, pede à psicologia são regras práticas" que ajudarão esses profissionais a melhorar as ideias, as disposições e a conduta das pessoas a seu cargo (p. 148). Na mesma linha, as duas frases de abertura do "manifesto behaviorista" de Watson (1913) são bem conhecidas: "A psicologia, como o behaviorista vê, é um ramo puramente objetivo da ciência natural. Seu objetivo teórico é a previsão e controle do comportamento" (p. 158). Aqui podemos ver que, muito cedo na análise do pensamento científico, o valor de uma declaração científica

\footnotetext{
${ }^{1}$ N. do T.: a obra de Mach (1886/1959), A análise das sensações e a relação do físico com o psíquico, se preocupa centralmente em compreender a construção do conhecimento sobre a natureza a partir do exame empírico das sensações do conhecedor. O excerto do qual a citação destacada pelo autor é extraída, que talvez soe difícil de compreender sem contextualização, termina com a frase: “... o impulso puro em direção ao conhecimento ainda é um ideal
}

fora avaliado em termos de sua contribuição para a ação efetiva, como previsão e controle.

Embora B. F. Skinner fosse um psicólogo experimental e não um filósofo, grande parte de seu trabalho também abrangia o pragmatismo. Um exemplo é quando Skinner (1974) disse que "conhecimento científico é comportamento verbal.... É um corpus de regras para a ação efetiva ... [A] proposição é verdadeira na medida em que, com sua ajuda, o ouvinte responde efetivamente à situação que descreve" (pp. 241-242). Esta passagem indica que Skinner subscreveu uma concepção pragmática da ciência, que enfatizava como os seres humanos poderiam interagir efetivamente com o mundo, ao invés da concepção tradicional de Verdade e Conhecimento como representação de uma realidade metafísica.

\section{PRAGMATISMO VS VISÕES TRADICIONAIS: PREVISÃO E CONTROLE}

Muitas visões tradicionais do conhecimento científico reconhecem a importância tecnológica da previsão e do controle; no entanto, argumentam que o conhecimento científico genuíno consiste em enunciados contemplativos sobre mecanismos teóricos ou estruturas que supostamente fundamentam as observações (Smith, 1992). Para este fim, leis, equações e modelos são considerados como a mais alta forma de conhecimento científico, na medida em que são mantidos para refletir as características operacionais dos mecanismos ou estruturas teóricas subjacentes. O controle é visto como um problema vulgar de engenharia, que decorre de como aplicar as formas contemplativas de conhecimento científico genuíno.

Certamente, esses são assuntos complexos. Por exemplo, uma visão tradicional e uma visão pragmática da ciência podem não diferir tanto quanto uma visão tradicional supõe. Grande parte da discussão gira em torno do papel da previsão: é uma propriedade formal de um sistema explicativo ou é importante por razões pragmáticas? Embora as visões tradicionais enfatizem suas propriedades formais, Skinner (1953) enfatizou a importância pragmática da previsão da seguinte maneira:

O "sistema" científico, como a lei, é projetado para nos permitir lidar com um assunto de maneira mais eficiente. O que chamamos de concepção científica de uma coisa não é conhecimento passivo. A ciência não está preocupada com contemplação. Quando descobrimos as leis que governam uma parte do mundo ao nosso redor, estamos prontos para lidar efetivamente com essa parte do mundo. Ao prever a ocorrência de um evento, podemos nos preparar para isso. Ao organizar as condições de maneiras especificadas pelas leis de um sistema, não apenas prevemos, nós controlamos; nós "causamos" um evento para que ocorra ou assuma certas características. (pp. 1314)

em nossas atuais condições sociais" (p. 23). Tratam-se de afirmações do início da obra, em que Mach (1886/1959) sinaliza para como as demandas práticas do ambiente social do cientista interferem no processo de conhecimento, de tal modo que a ideia da busca do conhecimento como um fim em si próprio (como um “impulso puro" por conhecer) não se sustenta. 
Da mesma forma, um modelo teórico pode informar os esforços para prever e controlar, identificando faixas de intervenções que podem ser realizadas, ou faixas de efeitos que podem ser esperados de uma dada intervenção. Nosso ponto aqui é que, em uma leitura pragmática, o que aparece como uma visão distinta e alternativa pode ser vista como diretamente relevante para uma visão pragmática do conhecimento científico.

\section{POR QUE O PRAGMATISMO NÃO É SIMPLESMENTE INSTRUMENTALISMO?}

Um tópico que está nominalmente relacionado ao pragmatismo é o instrumentalismo. O instrumentalismo é a tese, nas visões tradicionais, de que um dos objetivos da ciência é simplesmente propor conceitos que gerarão previsões testáveis. Quando esses conceitos são verificados por meio da pesquisa, eles são incorporados à teoria, que é o objetivo final da ciência. Nesta visão, os cientistas não precisam se preocupar com as origens dos conceitos. As origens podem estar no insight do cientista, mas, em qualquer caso, suas origens são incidentais à sua verificação e seu papel na construção da teoria.

Analistas do comportamento entendem que o pragmatismo e o instrumentalismo se sobrepõem em algum sentido, mas sugerem que o pragmatismo vai além do instrumentalismo, argumentando que, se algum conceito gera previsões testáveis e verificáveis, a questão importante é a base pela qual ele o faz. A origem do conceito não pode ser facilmente descartada, como no instrumentalismo. Em vez disso, os analistas do comportamento perguntam: que variáveis e relações o conceito leva em consideração? Como essas variáveis podem ser manipuladas para produzir um desfecho desejado? Estas perguntas se seguem diretamente de uma abordagem comportamental das fontes do comportamento verbal científico, em vez de uma abordagem tradicional em termos de referência e simbolismo. A clarificação e o refinamento das fontes do comportamento verbal aumentarão sua contribuição. O instrumentalismo não chega a fazer essas perguntas pragmáticas. Assim, para os analistas do comportamento, o pragmatismo não é equivalente ou redutível ao instrumentalismo.

\section{PRAGMATISMO E SIGNIFICADO CLÍNICO VERSUS ESTATÍSTICO}

Podemos ainda notar que cientistas e pesquisadores às vezes distinguem entre (a) o tamanho do efeito e significado clínicos, por um lado; e (b) valor de $p$ e significância estatística, em testes de hipótese nula, de outro. De acordo com essa distinção, alguns achados de pesquisa podem ser clinicamente significativos e informar manipulações que tenham o efeito prático desejado, e esses achados podem ser distinguidos de outros que podem ser estatisticamente significativos, mas que não atingem efeitos que sejam de magnitude suficiente para serem importantes por razões práticas. Quando cientistas e pesquisadores fazem essas distinções, eles certamente estão fazendo uma distinção pragmática sobre como a pesquisa pode identificar manipulações eficazes. Os analistas de comportamento enfatizam a importância dessa distinção e enfatizam a significância clínica, e não estatística, dos achados, sempre que possível.

\section{PRAGMATISMO E A RELAÇÃO ENTRE NEUROCIÊNCIA E ANÁLISE DO COMPORTAMENTO}

Para ver outras implicações das considerações pragmáticas na psicologia, podemos examinar três questões controversas: (a) a relação entre a neurociência e o estudo das relações comportamento-ambiente, (b) níveis de análise - a questão molar versus molecular, e (c) a relação entre mentalismo e análise do comportamento (por exemplo, Moore, 2016). Com relação à primeira questão, muitos pesquisadores e teóricos tradicionais argumentam que alguma forma de comportamento não foi realmente explicada até que algum mecanismo fisiológico subjacente ao comportamento tenha sido identificado. Em uma visão pragmática, notamos que este argumento é uma afirmação metafísica sobre em que consistem o Verdadeiro Conhecimento e a Verdadeira Explicação. Assim concebido, o argumento é inconsistente com uma orientação pragmática. Dizer que sabemos alguma coisa é dizer que podemos nos comportar efetivamente em uma circunstância ou outra. Dizer que explicamos alguma forma de comportamento é dizer que identificamos as variáveis e relações das quais é função, e pelas quais podemos controlá-la. Por exemplo, podemos fazer o comportamento aparecer ou desaparecer por comando, com as propriedades e a taxa, ou probabilidade, que desejamos. Em princípio, poderíamos ser capazes de prever e controlar o comportamento por meio de (a) uma intervenção fisiológica, por exemplo, administrando uma pílula ou uma injeção; ou (b) uma intervenção ambiental, por exemplo, manipulando uma contingência de reforço. A intervenção específica que empregamos pode depender dos recursos disponíveis para nós no momento e no cenário que queremos prever e controlar. Obviamente, nossa escolha de uma intervenção também depende de nosso nível de conhecimento sobre o comportamento em questão. No momento, estamos longe de ter um nível de conhecimento que facilite esse tipo de intervenção fisiológica eficaz. Nosso ponto aqui talvez seja abstrato: qualquer forma de intervenção - fisiológica ou ambiental - pode alcançar o fim desejado, e nenhuma forma é privilegiada por ser a base fundamental do outro. Pelo contrário, nossa escolha é uma questão de considerações práticas (por exemplo, Skinner, 1974, p. 221).

\section{PRAGMATISMO E NÍVEIS DE ANÁLISE}

O segundo assunto - o nível apropriado de análise para nossas alegações de conhecimento em psicologia também envolve considerações práticas. É uma questão empírica se uma dada classe de comportamento que desejamos influenciar - digamos, tornando o comportamento mais provável, se for atualmente deficiente, ou menos provável, se for excessivo - é função de eventos, variáveis e relações em maior escala, nível molar, ou em escala reduzida, nível molecular. Analistas do 
comportamento enfatizam que é útil para os cientistas permanecerem sensíveis a essa questão. Nossos métodos revelarão a resposta, como por meio de pesquisa controlada no laboratório, ou de análises funcionais em ambientes aplicados. Afirmações apriorísticas de que deveríamos trabalhar apenas em um ou outro nível, porque tal nível refletiria o nível metafisico Verdadeiro ou Real, não fornecerão a resposta.

\section{PRAGMATISMO E A RELAÇÃO ENTRE MENTALISMO E ANÁLISE DO COMPORTAMENTO}

A terceira questão diz respeito à relação entre mentalismo e análise do comportamento. Notamos que os analistas do comportamento se opõem ao mentalismo. Em uma interpretação pragmática, a oposição ao mentalismo baseia-se na ideia de que as teorias e explicações mentais não promovem a previsão e o controle efetivos. Por quê? Para analistas do comportamento, teorias e explicações mentalistas são amplamente ineficazes na previsão e controle, porque geralmente consideram a origem das variáveis mentais como autônomas e não uma função de contingências comportamentais e de seleção nos níveis de filogenia, ontogenia e cultura. A fonte de controle sobre o comportamento verbal mentalista está na tradição sociocultural, reificação e metáforas enganosas, em vez de observações de processos em andamento e extensões genéricas de nossas descrições. As previsões derivadas de teorias e explicações mentais podem, às vezes, parecer precisas e, portanto, úteis, mas para analistas do comportamento sua utilidade decorre da maneira como incorporam contingências comportamentais e de seleção ainda que implicitamente - nos níveis de filogenia, ontogenia e a cultura, em vez de incorporar variáveis mentais que são consideradas epistemologicamente superiores às variáveis comportamentais.

$\mathrm{Na}$ mesma linha, podemos examinar as objeções analítico-comportamentais ao mentalismo, que afirmam que estruturas e mecanismos mentais não existem e, portanto, não devem ser incluídos em teorias e explicações psicológicas. Se nós, como analistas do comportamento, argumentarmos desta forma, corremos o risco de sermos pouco pragmáticos e violar um de nossos princípios orientadores. Quando fazemos tais afirmações, estamos falando de forma metafísica, não diferente, em princípio, de um mentalista que argumenta que estruturas e mecanismos mentais obviamente existem e, portanto, devem ser incluídos em teorias e explicações psicológicas. Novamente, a questão é até que ponto uma afirmação científica contribui para previsão e controle. Sim, declarações mentais não contribuem muito para previsão e controle. A teoria da linguagem de Chomsky não ajuda muito os fonoaudiólogos a ensinar as crianças com repertórios verbais empobrecidos a fortalecer seus repertórios verbais. Pelo contrário, podemos, compreensivelmente, querer empregar teorias e explicações mais eficazes. Estas são teorias e explicações comportamentais. É suficiente dizer que elas devem ter preferência porque promovem melhor previsão e controle, e evitar debates acerca de ontologia, sobre os quais provavelmente não haverá resolução.

\section{CONCLUSÃO}

Em suma, adotando uma orientação pragmática, os analistas do comportamento podem se tornar melhores cientistas, prestadores de serviços e mesmo cidadãos, o que os possibilita contribuir melhor para o importante mundo dos assuntos humanos e do bem-estar humano.

Palavras e frases importantes: Instrumentalismo, mentalismo, metafísica, níveis de análise molares $v s$. moleculares, neurociência, pragmatismo, previsão e controle, verdade, realidade.

\section{REFERÊNCIAS}

Bacon, F. (1937). De dignitate et augmentis scientarium. In R. F. Jones (Ed. and Trans.), Essays, Advancement of Learning, New Atlantis, and other pieces (pp. 377-438). New York: Odyssey. (Original publicado em 1623)

Dewey, J. (1896). The reflex arc concept in psychology. Psychological Review, 3, 357-370.

James, W. (1892). A plea for psychology as a "natural science." Philosophical Review, 1, 146-153.

Mach, E. (1959). The analysis of sensations and the relation of the physical to the psychical. New York: Dover Publications. (Original publicado em 1886).

Moore, J. (2016). Behavior analytic pragmatism. Journal of Mind and Behavior, 37, 219-246. Skinner, B. F. (1953). Science and human behavior. New York: Macmillan.

Skinner, B. F. (1974). About behaviorism. New York: Knopf.

Smith, L. D. (1992). On prediction and control. American Psychologist, 47, 216-223.

Watson, J. B. (1913). Psychology as the behaviorist views it. Psychological Review, 20, 158-177.

Submetido em 28/05/2018 Aceito em 20/06/2018 